\title{
LEV ZELENY:
}

THE MOON IS 'THE SEVENTH CONTINENT" OF THEEARTH
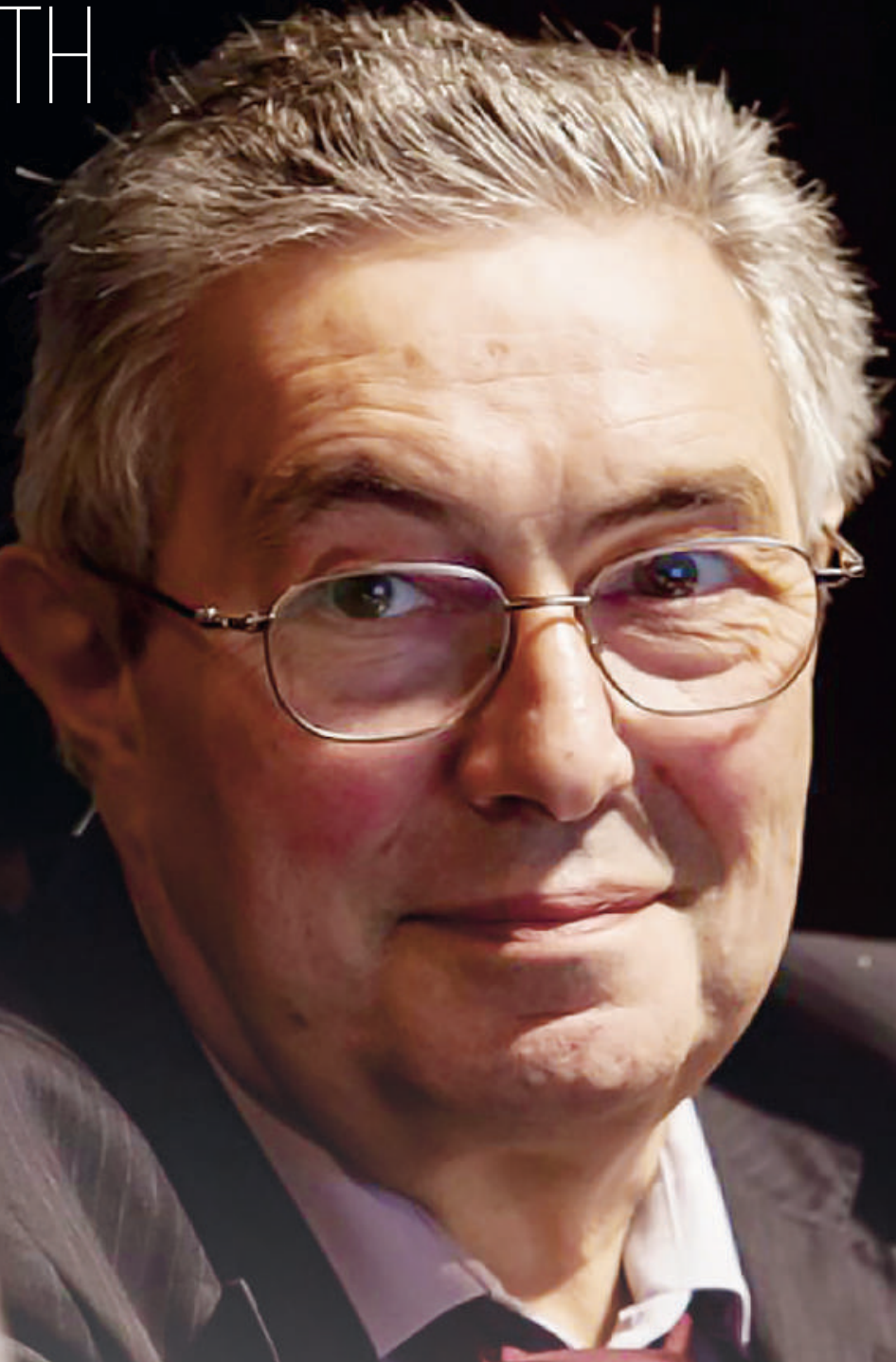

ЛЕВ ЗЕЛЁНЫЙ: ЛУНА - 《СЕДВМОИККОНТИНЕЕН ЗЕМЛИ 
Natalia L. BURTSEVA, Professor of RSUH Mass-Media Institute (Division for Journalism), Ph.D. student, Korolev, Russia, natalya.burtseva@rsce.ru

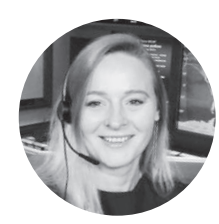

Наталья Леонидовна БУРЦЕВА, преподаватель факультета журналистики Института массмедиа РГГУ, аспирант, Королёв, Россия, natalya.burtseva@rsce.ru
ABSTRACT I 12 September 1959 the "Luna-

2" Soviet interplanetary automatic station was launched. 14 September 1959 it became the first vehicle that reached the lunar surface. That was the second successful launch in the framework of the "Luna" Soviet space programme. Our correspondent had a talk with the Academician of the RAS, Dr. Sci. (Physics and Mathematics), Professor Lev Matveyevich Zeleny. The following topics were discussed: the beginning of deep space exploration, why the rotational method is the best for lunar development, what lunar dust is hazardous to.

Ключевые слова: the "Luna-2" Soviet interplanetary automatic station, solar wind, the Moon impact make-up model, space radiation, gravity, lunar dust, Lunar Reconnaissance Orbiter, lunar research neutron detector
АННОТАЦИя I 12 сентября 1959 года была запущена советская межпланетная автоматическая станция «Луна-2». 14 сентября 1959 года именно этот аппарат впервые достиг поверхности Луны. Это был второй успешный запуск в рамках советской космической программы «Луна».

О начале изучения дальнего космоса, о том, почему вахтовый метод - лучший для освоения Луны и чем опасна лунная пыль, наш корреспондент побеседовал с академиком РАН, доктором физико-математических наук, профессором Львом Матвеевичем Зелёным.

Ключевые слова: межпланетная автоматическая станция «Луна-2», солнечный ветер, модель ударного формирования Луны, космическая радиация, гравитация, лунная пыль, Lunar Reconnaissance Orbiter, лунный исследовательский нейтронный детектор

\section{- Как в вашу жизнь вошел космос?}

- Я с детства интересовался историей изучения и покорения космоса. Прочел книги Б. Е. Чертока, все четыре тома, что называется, от корки до корки. Я был восхищен мужеством и настойчивостью наших предшественников, тем, как много они сделали, несмотря на колоссальные трудности. Но в определенном смысле им было легче. Мы сейчас жалуемся на недостаток времени, денег, внимания руководства - у них все это было. Благодаря этому они и открыли дверь в космос. Конечно, их достижения мотивировались политикой, соревнованием с американцами, но это не умаляет их вклада в науку. И даже кажущиеся неудачи первых проектов оказывались удачными.

В начале 1950-х годов американский теоретик Юджин Паркер предположил, что солнечная ко-

ДАЖЕ КАЖУЩИЕСЯ НЕУДАЧИ ПЕРВЫХ КОСМИЧЕСКИХ ПРОЕКТОВ ОКАЗЫВАЛИСЬ УДАЧНЫМИ. рона не находится в равновесии, так как плазма должна постоянно растекаться, ускоряясь. В честь Паркера американцы назвали новую миссию, которая сейчас летит к Солнцу, космический зонд «Паркер». Но в то время его догадка повисла в воздухе. Никто не мог проверить ее, потому что космические аппараты первых лет летали около Земли. А Земля закрыта от Солнца и его плазмы достаточно мощным магнитным полем. Это были годы великих открытий околоземного космоса, но дальний за пределами 100 тысяч километров, где перестает действовать магнитная оболочка земли, - был неизвестен.

\section{- Выходиm, чmo annapam «Луна-1» открыи сол- нечный ветер?}

- Выходит, так. Советский аппарат "Луна-1» вышел в дальнее космическое пространство и направился к Луне. На нем были установлены плазменные датчики - они и зафиксировали мощный поток в абсолютной пустоте.

Оказалось, что пространство между Землей и Солнцем заполнено горящей, быстро движущейся (300-40о километров в секунду), но очень разреженной плазмой - в одном кубическом сантиметре всего несколько частиц. 


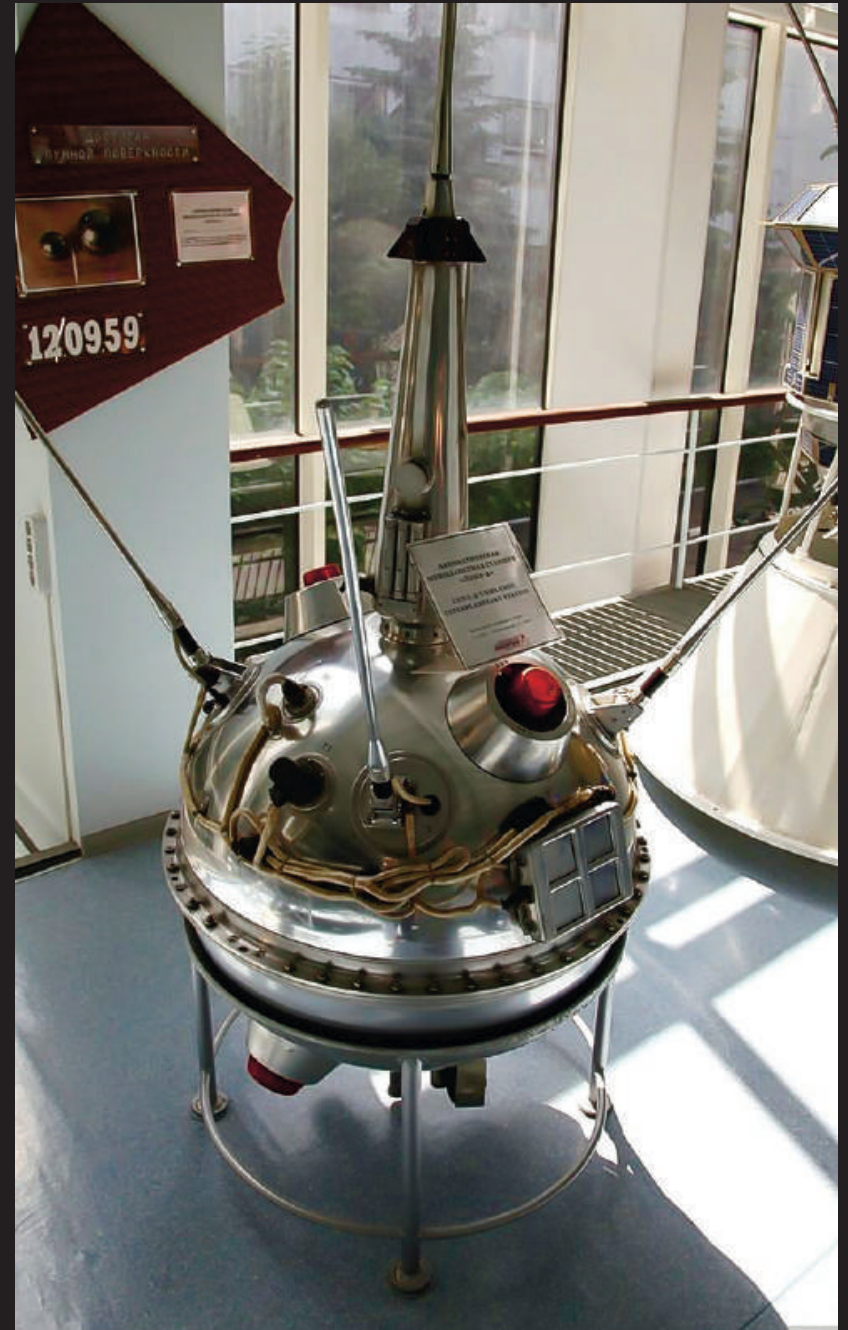

Annapam «Луна-2» в музее РКК «Энергия»

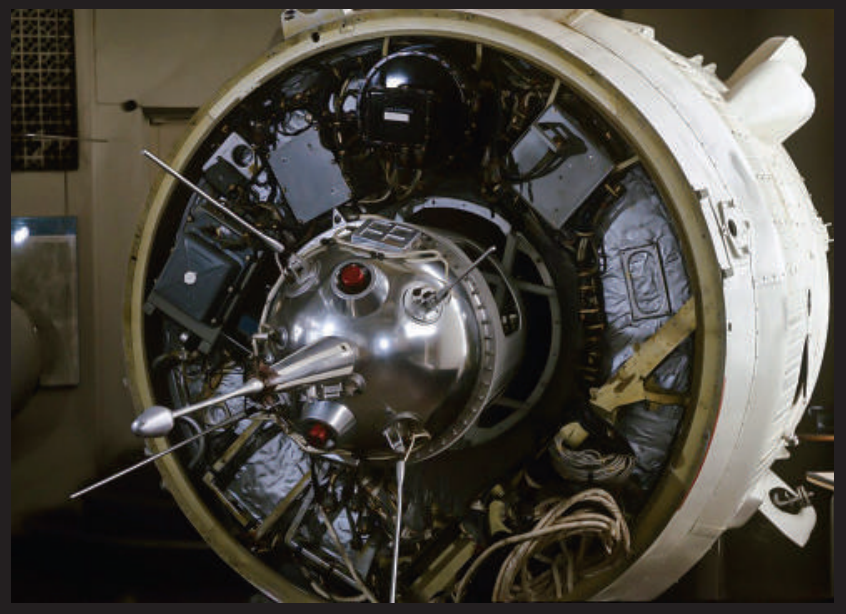

Annapam «Луна-2» и третья ступень ракеты-носителя

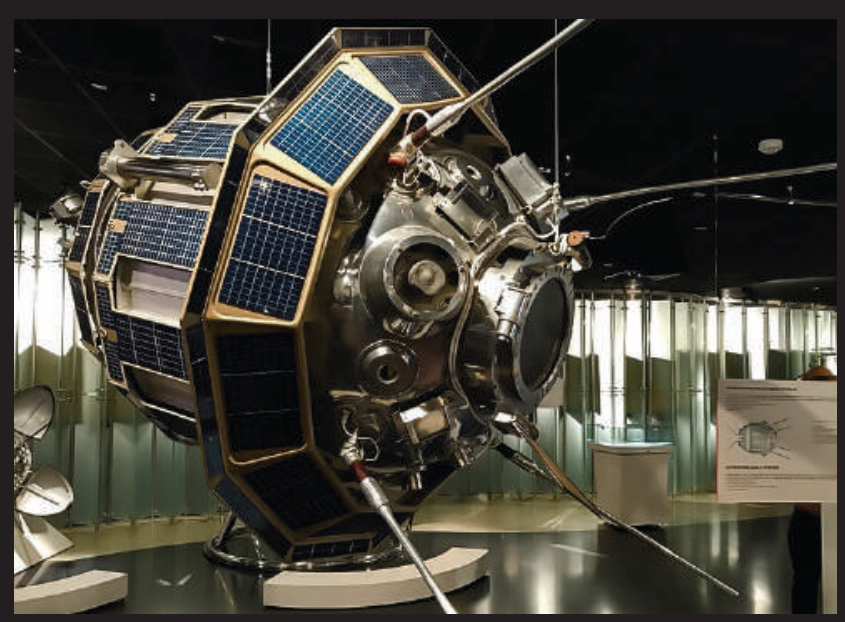

Макет аппарата «Луна-3»
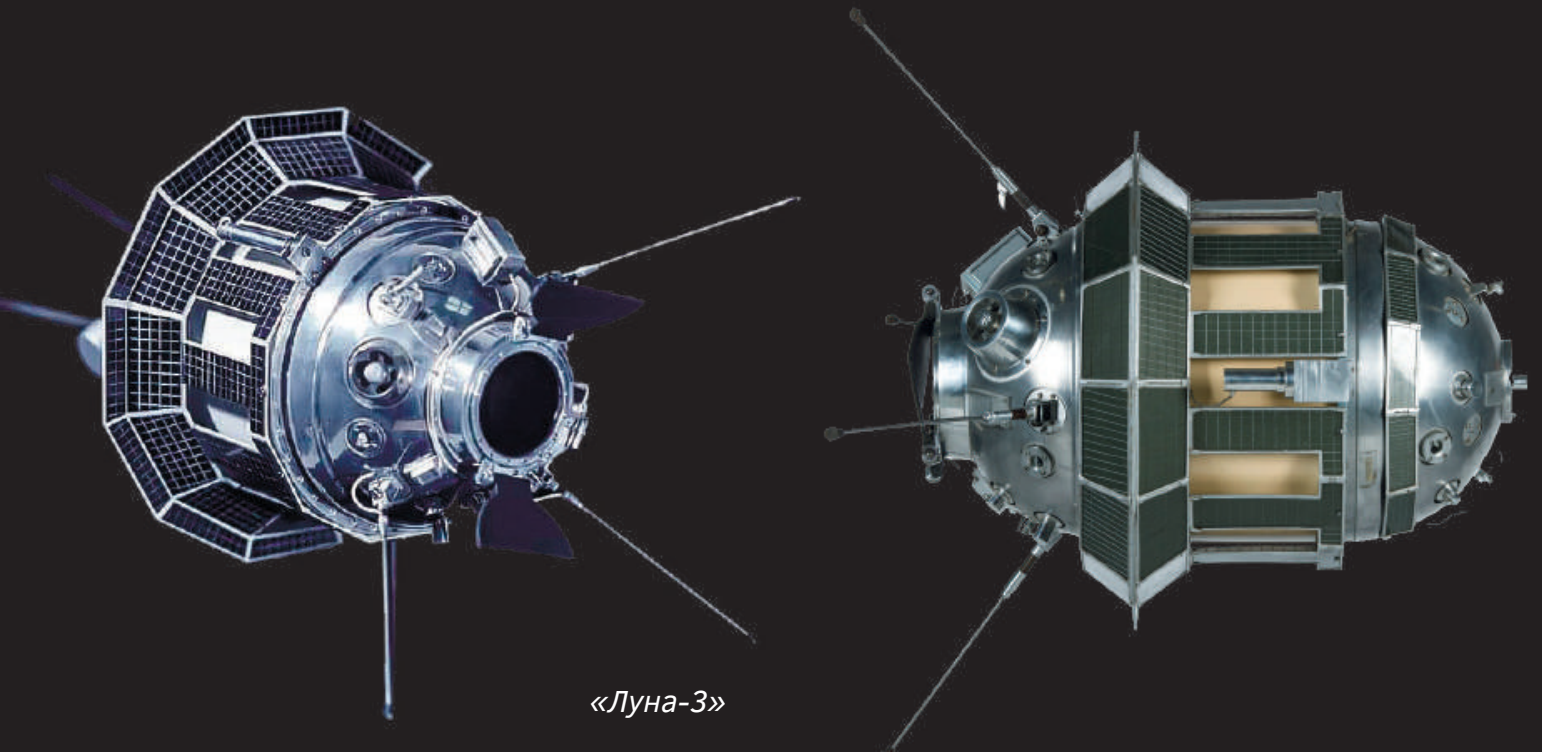


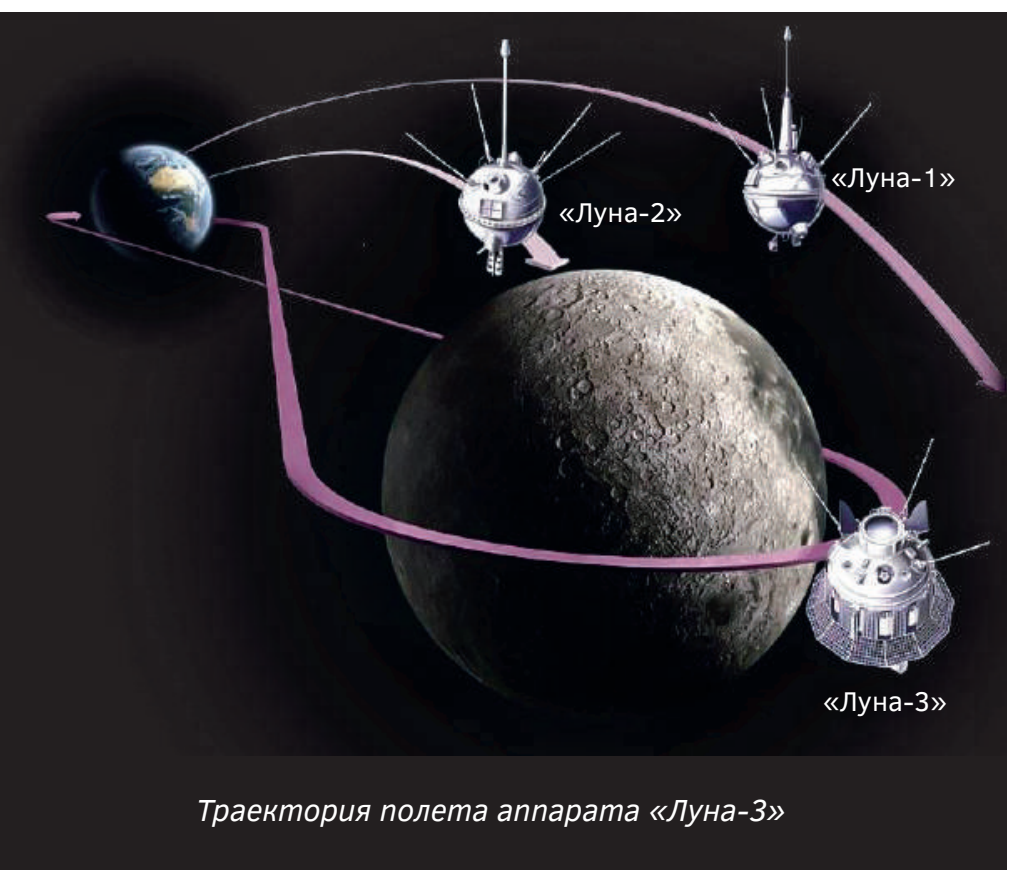

фактор учитываем, но, быть может, недооцениваем. Последние исследования российских ученых из Института медико-биологических проблем РАН (ИМБП) показали, что в составе радиации присутствуют не только солнечные частицы, но и очень тяжелые частицы лучей космических энергий, которые имеют такую пробивную силу, что могут повреждать нервные клетки. То есть речь идет не о каких-то отдаленных последствиях типа лучевой болезни, но о немедленных поражениях когнитивных функций. Естественно, подобные эксперименты над человеком никто не ставил. За то короткое время, на которое астронавты "Аполлона» летали на Луну, эффекты могли не проявиться. Это редкие риски, но от них невозможно защититься, потому что они не изучены и, следовательно, непредсказуемы.

Солнечная радиация немного слабее, и за эти годы мы научились предсказывать ее действие.

Перелет до Луны занимает немного времени, а на Луне можно построить укрытие. Это не так сложно - полтора-два метра лунного реголита дадут достаточно хорошую защиту, которую не смогут пробить опасные частицы. Можно делать по предложению Бармина - ставить конструкции и сверху насыпать реголит. Это один из вариантов, есть и другие решения. Таким образом, от радиации, помимо короткого времени перелета, можно защититься.

\section{НЕОБХОДИМО ВОССТАНОВИТЬ ОТЕЧЕСТВЕННЫЕ ТЕХНОЛОГИИ лУННОЙ МОБИЛЬНОСтИ.}

Второй фактор - гравитация. Космонавты привыкают к невесомости, в которой проводят по полгода - но это требует постоянных упражнений. На луне гравитация одна шестая, и этот уровень никто никогда не воспроизводил. Сейчас даже нет возможности ответить на вопрос: как будет реагировать на нее человеческий организм? Как на близкую к нормальной земной гравитации или как на невесомость?

Вероятнее всего, люди, которые проведут на Луне несколько лет, смогут адаптироваться, но на Землю они никогда не вернутся: их кости станут слишком слабы. Это билет в один конец.

И третий фактор - лунная пыль, то, чем я сейчас как раз занимаюсь. С точки зрения специалиста по плазме лунная пыль очень интересна. Она похожа на плазму, но состоит не из неонов и электронов, а из тяжелых пылевых частиц размером в десятки и сотни нанометров, до микрона. Эти частицы заряжаются за счет фотоэффекта от солнечного излучения, приобретают заряд и начинают парить. Образуется среда пылевая плазма, она очень липкая. Американский астронавт Серна много писал об этом. На всех астронавтов налипала эта пыль и вызывала раздражение, вплоть до воспалений. Если посмотреть на известную фотографию Юджина Серна, можно увидеть, что вся его кожа в повреждениях от лунной пыли. Пахнет она, по его описанию, как использованный порох. Они знали об этой опасности, но полностью так и не смогли от нее предохраниться.

По всей видимости, лунная пыль будет большой проблемой еще и потому, что она наэлектризована.

Все это говорит о том, что ко времени прилета человека на Луну автоматы уже должны будут построить укрытия, обеспечить средства защиты.

\section{- Луна интересна и важна в изучении, почему же иунная программа так нестабимьна?}

- Дело в том, что не было определенных и утвержденных задач для нее. Но сейчас ситуация изменилась. В конце 2010-х годов заработал наш прибор на американском аппарате ЛРО (Lunar Reconnaissance Orbiter) - Land, который показал, что в полярных областях Луны есть запасы воды под поверхностью. Это дало новый импульс всем лунным исследованиям: стало ясно, что там делать и что искать. Полярные области в то время никто не исследовал. И наша нынешняя программа заострена на их изучении. Мы делаем два посадочных аппарата. Один должен улететь в 2021 году, другой - в 2023-2024-м - «Луна-25» и «Луна-27», и орбитальный аппарат - в 2026 году.

Такие значительные номера оттого, что мы ведем счет от советских аппаратов, последний 
из которых назывался "Луна-24" (1976 год). Так мы утверждаем, что, по выражению Ньютона, "стоим на плечах великих предшественников".

\section{- Что наука сегодня может дать производству и наобороm?}

- РКК «Энергия» сейчас занята пилотируемой частью этой программы. Раньше работа велась раздельно: что-то делали в Академии наук, что-то - в НПО имени С. А. Лавочкина. Сейчас возникает целостная программа. Она состоит из двух частей: проекты по федеральной космической программе и проекты по сверхтяжелой ракете. Последняя как раз создается в РКК "Энергия", и туда включены работы, непосредственно не связанные со сверхтяжелым носителем, но связанные с освоением Луны.

Конечно, для освоения Луны нужны серьезные технологии, но прежде всего - мобильность. В этом смысле интересны и перспективны лунные роверы - луноходы, которые были изобретены у нас в стране. Но уже нет ни людей, ни предприятий, производящих эти замечательные конструкции. Я считаю, что технологию лунной мобильности нужно восстановить. Также необходимо разработать методики строительства убежищ - сейчас есть только наметки в этом отношении. Нельзя забывать и о поисках новых источников энергии: вся эта техника потребует большого ее количества. Полярные области Луны не богаты светом - поэтому там и сохранился водяной лед. Солнечной энергии будет недостаточно: на Луне потребуется ядерная энергетика. И этим уже занимаются наши ученые.

\section{- Какую роль сыграли "Луна-1", «Луна-2» и другие annapamb в изучении спутника Земпи?}

- Первое столкновение с Луной - первое попадание того, что сделано на Земле, на другое небесное тело - можно, в определенном смысле, сравнить с первым шагом человека по Луне. Это действительно историческое достижение, так же как облет планеты и фотографии обратной стороны. Они вышли не особенно качественными, но мы впервые увидели Луну с этого ракурса и узнали, что там все по-другому. Вне всякого сомнения, это связано с историей возникновения планеты, с некими мощными воздействиями.

Относительно обратной стороны Луны тоже есть мысли и планы. В частности, на ней можно разместить радиоастрономические комплексы: ведь они будут полностью защищены от электромагнитных воздействий Земли, и, следовательно, появится возможность получить высокую электромагнитную частоту.

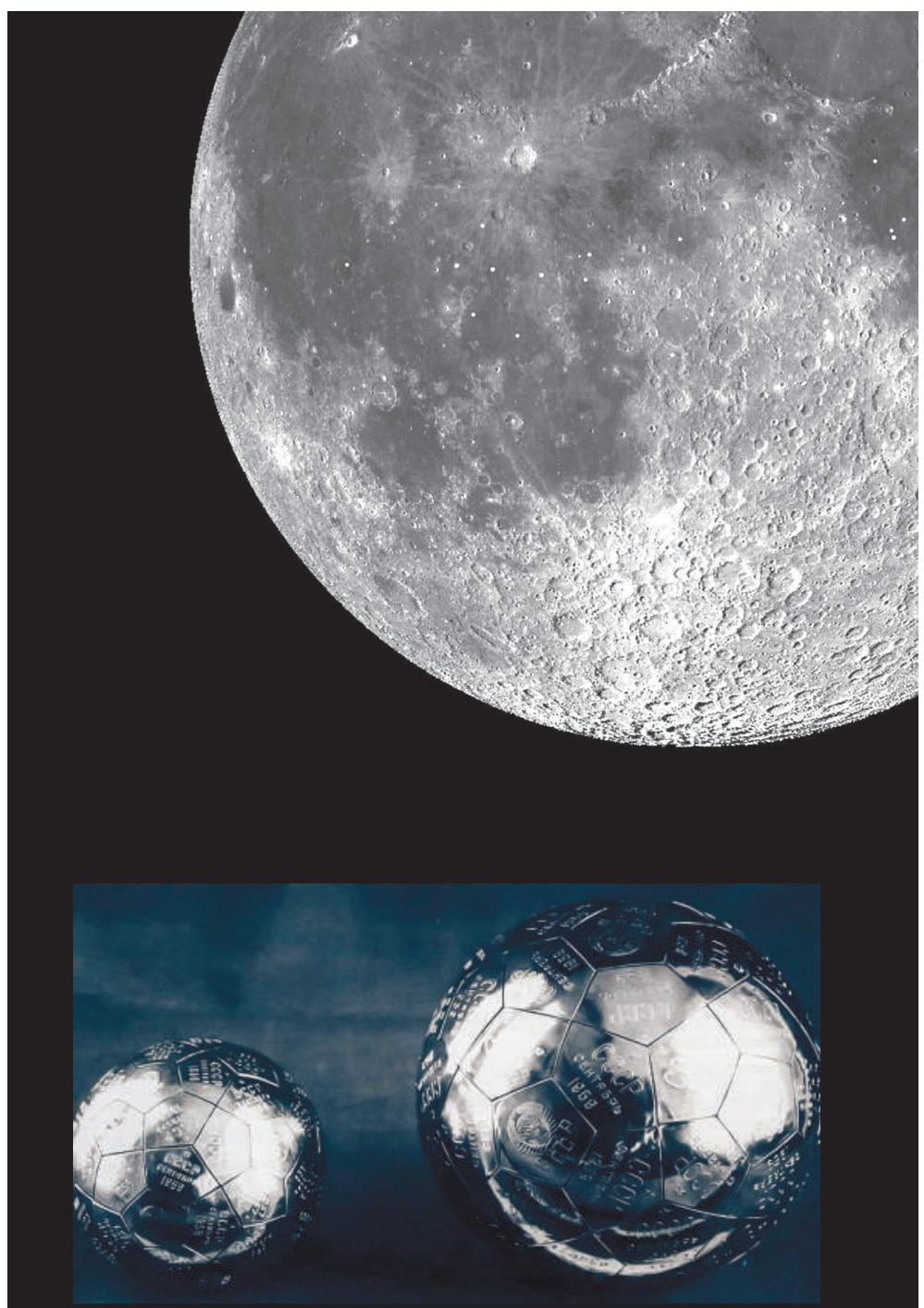

Вымпел апnарата «Луна-2»

(С Бурцева Н. Л., 2019

История статьи:

Поступила в редакцию: 12.08.2019

Принята к публикации: 27.08.2019

Модератор: Плетнер К. В.

Конфликт интересов: отсутствует

Для цитирования:

Бурцева Н. Л. Лев Зелёный: Луна - «седьмой континент» Земли // Воздушно-космическая сфера. 2019. №3. С. 10-15. 